\title{
Juventudes, Poder y lo Político: CONCEPTOS EN TRÁNSITO
}

\author{
NATALia HERNÁNDEZ MARY ${ }^{1}$
}

\begin{abstract}
RESUMEN
El presente artículo es una invitación a reconocer las diversas construcciones que realizan sujetos jóvenes, agrupados en torno a nociones de poder, juventudes y lo político. Dichos conceptos (en general) se manejan en un discurso cotidiano y 'común', sin embargo, desafían la operacionalización de los mismos. Dicho ejercicio se realizó en el marco de un trabajo indagativo que buscó conocer cuáles son los sentidos y cómo se concretizan estas nociones, en los espacios de las acciones sociales. Se escogió una metodología cualitativa y, como técnica, las entrevistas grupales. Estas elecciones permitieron abordar los tránsitos entre los sistemas de valor y las acciones materiales.

A través de este trabajo, fue posible visibilizar las transformaciones en torno a los sentidos que se le otorgan a las nociones, y cómo éstas transitan desde ejes conservadores a contemporáneos y viceversa. Hay una tensión constante entre lo abstracto y lo material de estas ideas fuerzas, ya que -según lo que indican los participantes- las acciones exigen un nivel de coherencia depurado. Para esta reflexión, se hará una revisión descriptiva de los hallazgos trabajados.
\end{abstract}

PAlabras Claves: JuVENTUdes - PODER - LO POLÍTICO

\footnotetext{
${ }^{1}$ Chilena. Dra. (c) en Trabajo Social, Universidad Nacional de la Plata - Argentina. Magíster en Trabajo Social, Pontificia Universidad Católica de Chile; Licenciada y Trabajadora Social, Pontificia Universidad Católica de Chile; Diplomada en Mundos Juveniles, ACHNU-Universidad de Chile.
}

Académica del Departamento de Trabajo Social, Universidad Alberto Hurtado. nhernand@uahurtado.cl 


\title{
Juventudes, Poder e o Político: Conceitos em trânsito
}

\begin{abstract}
RESUMO
O seguinte artigo é um convite a reconhecer as diversas construções realizadas por sujeitos jovens agrupados, em torno de noções de poder, juventudes e o político. Estes conceitos (em geral) são tratados em um discurso cotidiano e "comum”, no entanto, desafiam a operacionalização dos mesmos. Este exercício foi realizado no marco de um trabalho indagativo que visou conhecer quais são os sentidos e como são concretizadas estas noções, nos espaços das ações sociais. Foi utilizada uma metodologia qualitativa, e como técnica as entrevistas grupais. Estas eleições permitiram abordar os trânsitos entre os sistemas de valor e as ações materiais.

Através deste trabalho, foi possível visibilizar as transformações em torno dos sentidos são outorgados às noções, e como estas transitam desde eixos conservadores a contemporâneos e vice-versa. Há uma tensão constante entre o abstrato e o material destas ideias forças, já que - segundo o que indicam os participantes- as ações exigem um nível de coerência depurado. Para esta reflexão, será feita uma revisão descritiva dos resultados trabalhados.
\end{abstract}

PALAVRAS-CHAVE: JUVENTUDES - PODER - O POLÍTICO.

\section{Youth, PoWer AND Politics: IN-PROgRess CONCEPTS}

\begin{abstract}
The following article is an invitation to recognize the different constructions made by young subjects gathered around notions of power, youths and politics. These concepts are generally handled in a daily and 'common' discourse that nonetheless challenge their own operationalization in the context of an investigatory work into the senses and notions and how they materialize in the spaces of social actions. On the basis of a qualitative methodology, with group interviews as the main data collection technique, we were able to approach the transits between the systems of value and material actions.

The results of this work brought attention to the sense-related transformations given to the notions and how they move from conservative to contemporary axes and vice versa. The abstract and the material forces of these driving ideas are constantly in tension since - according to participants' feedback - a refined level of consistency is required for actions. A descriptive review of the findings will be made in order to help further reflection.
\end{abstract}

KEYWORDS: YOUTH - POWER - POLITICS. 


\section{INTRODUCCIÓN}

El momento socio político que vivencia Chile, posibilita la elaboración de plataformas para observar y aprender de las transformaciones que emanan desde demandas propias de los distintos actores sociales que componen la trama en cuestión. Dentro de estos actores, es posible reconocer a las y los jóvenes que, a través de diversas formas de conglomerarse, han logrado generar una visibilidad y posicionamiento, que a lo menos, cuestiona órdenes establecidos desde matrices hegemónicas.

Así, el interés por las y los jóvenes, está vinculado a las formas de construcción a las que se ven enfrentados, pues - en general- las matrices hegemónicas (de ordenamientos) los ubica en posiciones opuestas: como sujetos incompletos (insuficientes) o bien como los salvadores de un futuro (sin ser concebidos como presentes contextualizados). En general, dichas creencias se sustentan alejadas de atributos relacionados a las potencialidades y características que ponen en relación en un espacio/tiempo del aquí y ahora. Lo anterior se entrelaza con las nociones de poder que hacen referencia a las ideas de fuerzas vinculadas entre actores y sus contextos. Esta intersección genera una óptica para identificar las acciones que jóvenes realizan en los espacios políticos, en búsqueda de cambios sociales.

Con estos elementos vinculados, surge el cuestionamiento por conocer cómo significan las y los jóvenes que participan en acciones colectivas en lo público, la noción y las relaciones de poder. Cuestionar y reconocer cómo esas significaciones se operacionalizan en sus estrategias. 
Juventudes, poder y lo político, es una triada de conceptos que se entrelazan en ciertas construcciones de dispositivos interventivos ${ }^{2}$, aportando complejidad a las comprensiones como también a los artefactos de operacionalización que se utilizan en pos de la transformación social.

Dichas relaciones fueron utilizadas (en el proceso indagatorio) para generar un zoom, y a través de él, reconocer estrategias de intervención que agrupaciones sociales de jóvenes, utilizan en sus apuestas políticas. El ejercicio de acercamiento que se utilizó, asumió como desafío incorporar tanto los significados de los participantes, como sus manifestaciones tangibles. Resulta interesante revisar cómo estas construcciones se mueven desde espacios inmateriales a materiales, en función de la comprensión y las acciones que se fomentan a partir de ellas.

El presente artículo se desprende del proceso de elaboración de la tesis doctoral, cuyo objeto de estudio se centró en conocer cómo se operacionalizan las nociones de juventudes, poder y lo político, en las acciones interventivas de agrupaciones juveniles. Para ello, se escogió como eje articulador la noción de 'poder', construida desde lineamientos que provienen de los postulados de Michel Foucault. Esta mirada permite discutir las imágenes imperantes, que lo asocian a jerarquía, dominación, dictadura, entre otras.

Construir la idea de poder desde las posibilidades que brinda la línea post-estructuralista, es vincularlo a la noción de atributo presente en la construcción de todo sujeto social, el cual, se manifiesta en los espacios de

\footnotetext{
${ }^{2}$ La idea de dispositivo de intervención hace referencia a las construcciones teóricas conceptuales y metodológicas, que se ponen en movimiento en pos de transformar situaciones sociales construidas por el interventor social. Con ello no se piensa en un trabajo individual y/o dictatorial, sino que se apuesta a un trabajo elaborado desde los ejes que lo contextual exige hoy por hoy. Ejemplo de ello es la conjugación de las subjetividades que se relacionan en un mismo tiempo- espacio.
} 
relación constantes. Dicha noción facilita cuestionar las formas en que se piensan, reflexionan y ejecutan los procesos interventivos ${ }^{3}$.

La investigación consideró en su realización, el trabajo con nueve organizaciones sociales de la Región Metropolitana de Santiago de Chile, las cuales tienen como rasgo característico que fueron fundadas por jóvenes (y actualmente son jóvenes los que participan), poseen un funcionamiento cotidiano, y declaran su intención de transformación (en las temáticas que abordan) en los espacios públicos.

Como resultado de este proceso, se aprecian construcciones de las tres concepciones en tensiones constantes entre elementos conservadores y las apuestas de miradas deconstruidas desde lógicas contemporáneas. Lo anterior desde un movimiento de traslación desde concepciones abstractas a la aplicación de las mismas en sus espacios de intervención.

Lo anterior será abordado a través de una presentación conceptual de las tres ideas fuerzas mencionadas, para luego dar paso, a la descripción de la metodología utilizada en la investigación. En un tercer apartado, se presentarán los hallazgos centrales, para finalmente dar cuenta de las conclusiones.

\section{JUVENTUDES E INTERVENCIONES SOCIALES}

Cuando se realizan revisiones históricas en torno a la categoría teórica de juventudes, se reconocen 'nociones' que dan cuenta de diferentes significaciones. Dentro de este grupo de significaciones podemos reconocer dos líneas que se contraponen (pero que a la vez conviven). Por una parte están las miradas que se enfocan en el déficit y otras que los posesionan como salvadores de la situación actual (Duarte, 2015). Ambos polos, son imágenes

\footnotetext{
${ }^{3}$ Los procesos de transformación implica reconocer las tensiones constantes entre las elaboraciones de sujeto, fenómeno social y sitios, reconociendo que en ellas, se comparten categorías de comprensión.
} 
de 'una' juventud construida desde las miradas fijas, elaboradas por otros actores que no incorporan la propia mirada de los involucrados.

Si bien son posiciones que se ubican en polos distintos, presentan un elemento común que es de interés para esta reflexión: se construyen alejadas de la noción de poder. Aquí se hace referencia a una noción contemporánea, ya que se recurre a los aportes que brindan las ideas abordadas desde Foucault, las cuales apuestan a terminar con la desvalorización y/o invisibilización de los sujetos. El concepto 'poder', ayuda a construir juventudes desde un prisma de reconocimiento en los tiempos presentes.

Abordar la idea de poder desde la mirada de Foucault, permite visibilizar construcciones de sujetos sociales con capacidades de tomar decisiones, autogobierno y de relacionarse con otros. Este escenario permite generar un ejercicio de deconstrucción que dé cabida al reconocimiento de sus actorías y su relación crítica con los dispositivos de intervención, siendo interesante develar cómo se incorporan los atributos de poder por parte de los sujetos ${ }^{4}$.

Pelegrí (2004) define poder como un "hecho social perceptible en la realidad, pero que no se circunscribe sólo al gobierno de una nación o Estado, sino que implica a todo el cuerpo social como resultado de las múltiples interacciones” (Pelegrí, 2004: 23). Tensionar los conceptos de juventudes y lo político desde las posibilidades que brinda comprender la noción de poder como: capacidades, aptitudes y responsabilidades, es decir, atributos que constituyen las elaboraciones de las categorías de sujetos individuales y colectivos.

\footnotetext{
${ }^{4} \mathrm{La}$ referencia que se hace aquí de poder, tiene relación con las facultades que poseen los individuos de "tomar" las opciones que más les acomoden, frente a las ofertas de elección que se encuentran presentes en su medio social. "Por poder se entiende cada oportunidad o posibilidad existente en una relación social que permite a un individuo cumplir su propia voluntad" (Weber, M. "Conceptos Sociológicos Fundamentales”. Editorial Alianza, 2006(1920): 208).
} 
Dicho ejercicio posibilita encontrar opciones de reconfigurar al momento de pensar en los sujetos sociales, y las relaciones que establecen. Se abre un campo visual que permite reconocer en ellos (y sus construcciones), los diversos aportes que realizan a los tejidos sociales. Rompiendo de esta manera, las imágenes fijas que se presentan en lo cotidiano. Incorporar las nociones de poder al momento de construir a los sujetos sociales, fomenta una gama de artefactos comprensivos que incorporan al propio actor, sus experiencias, historias, como también, los fenómenos sociales con los que se relaciona. Y en estas relaciones dialécticas, también interroga a los procesos de intervención social contemporáneos.

Conceptos que incorporen una relación con la idea de atributo (que oferta el abordaje de poder), permite visualizar opciones de interacción con sujetos integrales, y no con aquellos que se constituyen desde la estigmatización deficitaria y/o la santificada, que son ejemplos de nociones hegemónicas que se han incrustado en ciertos tejidos sociales. Genera un desafío constante, en cuanto a los mecanismos de acercamiento, puesto que posibilita finiquitar aquellas tensiones contradictorias que los visualizan desde posiciones dominadas, las cuales se centran en lógicas anulantes, que conllevan a una invisibilización permanente. Además, posibilitan reconocerles desde procesos coherentes que son posibles de incorporar en diversos espacios sociales, aunando miradas en pos de complejizar los procesos de intervención que se diseñan constantemente.

Ahora bien, las construcciones en torno a los sujetos sociales desde las nociones de poder se ponen en tensión al momento de buscar la coherencia entre dichas elaboraciones con los procesos de transformación; puesto que, las constituciones de estas miradas, se presentan como partes de las cartografías de navegación que se pueden desarrollar en las intervenciones sociales con jóvenes. De esta manera los diseños y las ejecuciones de los procesos de intervención, confluyen en función de las elaboraciones que se realizan. 
Se hace necesario señalar que los procesos de transformación, serán revisados desde las lógicas que aporta el trabajo social contemporáneo. Desde esta esfera se comprende la intervención social como un conjunto de acciones (en pos de un horizonte de transformación) que son ordenadas, planificadas, en función de las construcciones que se realizan, conjugando en ellas, estrategias y metodologías (Matus, 2007).

Cazzaniga (2005) indica que la intervención social es un constructo de un espacio y tiempo, de un momento en que se realiza, con diferentes actores involucrados. A partir de lo que indica la autora, es posible identificar que la intervención no es entendida únicamente como un accionar privativo de los profesionales, más bien, es reflejo de la complejidad de los contextos, en donde los diversos sujetos son parte de los movimientos que se generan desde las tensiones que se desarrollan. Se reconoce que la construcción de los sujetos sociales, son fundamentales al momento de concebir los procesos de intervención social.

Las lógicas disciplinares de Trabajo Social se han consolidado en innovaciones de modalidades de intervención privilegiando la participación de los sujetos involucrados y gestando algunos mecanismos de diálogo comunicativo, como forma activa de connotar el respeto por la dignidad de los sujetos. Así, podemos afirmar que Trabajo Social pone al centro, la necesidad de generar las condiciones sociales del diálogo, del reconocimiento de su importancia, y de las vías múltiples de su ejercicio, que generan las condiciones posibles de una gestión social co-responsable y más exitosa (Matus, 2007).

Las construcciones desde las nociones de poder implican nuevas formas de mirar, comprender y elaborar las relaciones que se construyen con los contextos. Lo anterior debido a que impacta las alternativas de conformación de los mismos, y por ende, se presenta como un desafío el generar teorías sociales que permitan sustentar estrategias metodológicas que orienten la intervención, 
brindando los andamios necesarios para operacionalizar la categoría de poder en los diversos constructos que las intervenciones plantean.

El proceso investigativo que inspira este artículo, pone en su centro el análisis del despliegue de la categoría de poder en las concepciones y acciones que las agrupaciones juveniles generan en los espacios comunes/públicos. Se comprenderá (para esta investigación) la idea de “Agrupación Juvenil” como colectivos que reúne a diversos actores que declaran comunión entre un horizonte de acción definido; en sus inicios han sido generados por jóvenes lo que no implica que no se puedan reconocer otros sujetos (adultos, niños, entre otros).

Según Hannah Arendt, lo político es un espacio de libertad y decisión pública (Mouffe, 2007), en donde aflora la noción de consensos deliberativos; sin embargo hay otros autores que lo refieren como espacios de relaciones de poder, y por ende, de disensos. En palabras de Chantal Mouffe (2007), lo político es entendido "como la dimensión de antagonismo que considero constitutiva de las sociedades humanas” (Mouffe, 2007: 16).

De esta manera, surge la idea de comprenderlo como posibilidad privilegiada de abandonar las ideas de 'un fundamento último', cuestionando las nociones hegemónicas, en donde se le reconoce como el escenario de visibilidad de la institucionalidad social; es necesario revisar y analizar las débiles fronteras entre lo social y lo político, puesto que son inestables; exigen para sí desplazamientos y renegociaciones constante entre los actores sociales (Mouffe, 2007).

Lo político se presenta como la posibilidad de representación de las diversas relaciones de poder: "El poder es constitutivo de lo social, porque lo social no podría existir sin las relaciones de poder mediante las cuales se les da forma” (Mouffe, 2007: 25). Se da cabida a la idea de disenso y conflicto, procurando apartar valoraciones negativas (desde las socializaciones hegemónicas) que les han acompañado en sus constituciones. Aquí, es posible 
reconocer el disenso como una posibilidad de construcción y reconstrucción de ciudadanías que se potencien en pos de un bienestar individual y colectivo. Es por ello que esta elaboración de 'lo político' posibilita cuestionar aquello que ha sido entendido como el 'orden natural' de las institucionalidad y de la política clásica, entendido como "un conjunto de prácticas e instituciones a través de las cuales se crea un determinado orden, organizando la coexistencia humana en un contexto de la conflictividad derivada de los político” (Mouffe, 2007: 16).

Es un entramado de relaciones de poder (desde esta mirada de atributo), en donde se requiere reconocer las diferencias, las tensiones, asumiendo la posibilidad de las diferencias pero que no apunte a la destrucción de cualquier orden; hay un reconocimiento de vínculos comunes, de manera de no entrar en lógicas de enemigos. En ese sentido, un concepto que ilumina es la idea de 'agonismo', en donde se aprecian posiciones diferentes, que están en conflicto (desde espacios irreconciliables incluso), pero existe un verdadero reconocimiento por la diada ellos/nosotros, brindando legitimidad a los procesos de discusión (Mouffe, 2007).

La construcción de un dispositivo analítico, articulando nociones de poder, lo político, juventudes, agrupaciones, posibilita comprender cómo las estrategias interventivas han de potenciarse en funciones de responder a las demandas cotidianas, que no sólo se aprecian en manifestaciones masivas (para no confundir con la idea de marcha y/o movimiento), sino que están siendo parte de las acciones sociales que los actores han incluidos en su praxis. Hay una apuesta por analizar y comprender, cómo la reconstrucción de conceptos clásicos aporta a posibilidades de transformación que persiguen diversas disciplinas y, en especial, la del Trabajo Social.

Ahora, los conceptos que se han mencionado presentan desafíos actuales de comprensión y operacionalización de los procesos de transformación para la disciplina del Trabajo Social, como también para las 
Ciencias Sociales que asumen el compromiso por la transformación. Esto, ya que las nociones que se encuentran relacionadas a ellos, no son (ni tienen que serlo) de carácter hegemónico, lo cual exige que se desplieguen capacidades comprensivas en torno a ellos, y a la vez, que se puedan presentar a otros en pos de la ocupación de los discursos en el espacio común de compartir entendimientos y acciones.

\section{Cuadro 1.}

Poder/poderes. (Discusión conceptual que permite construir la perspectiva del investigador)
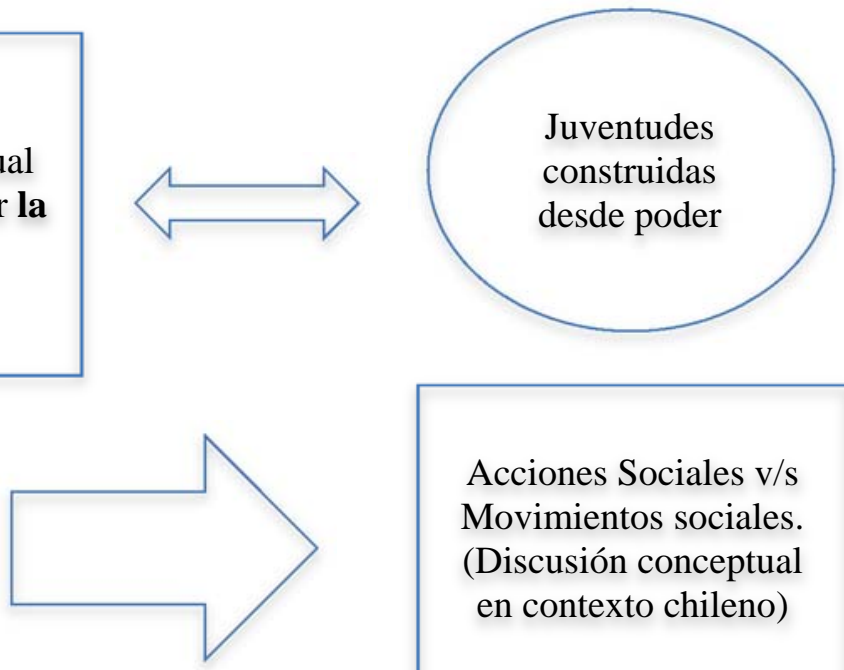

Acciones Sociales v/s Movimientos sociales. (Discusión conceptual en contexto chileno)
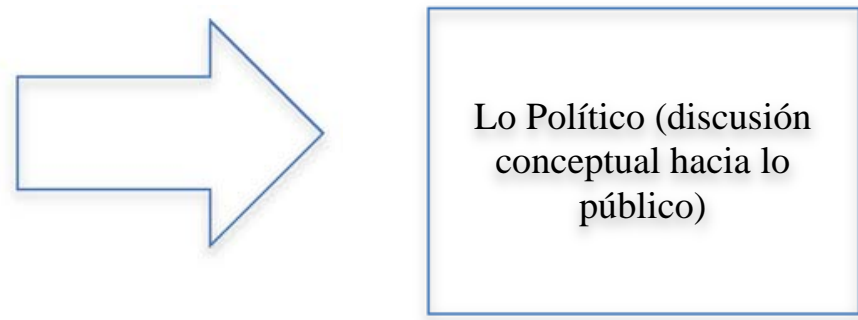

DISPOSITIVOS DE INTERVENCIÓN SOCIAL COMPLEJA como medio para fortalecer la construcción desde categorías de poder.

Dispositivo de intervención que reúna estrategias particulares

Cuadro de elaboración propia 


\section{Metodología}

Para la concreción de los objetivos propuestos, se optó por un enfoque cualitativo, lo que posibilitó la indagación de fenómenos sociales, a partir del sentido y/o interpretación que le otorgan las personas a dichas elaboraciones (Vasilichis, I: 2006). Facilitó un acercamiento a las propiedades que se otorgan a los fenómenos sociales, propiciando la producción de información a partir de "datos descriptivos: las propias palabras de las personas, habladas o escritas y la conducta observable” (Krause, M: 1995, pp.19-39).

El enfoque cualitativo no es reducible a un conjunto simple y prescriptivo de principios, puesto que se encuentra "fundada en una posición filosófica que es ampliamente interpretativa en el sentido de que se interesa en las formas en que el mundo social es interpretado, comprendido, experimentado y producido; basado en métodos de generación de datos flexibles y sensibles al contexto social en el que se producen; y sostenida por métodos de análisis y explicación que abarcan la comprensión de la complejidad, el detalle y el contexto" (Mason, J. en Vasilichis, I: 2006: 25).

En este sentido utilizar el enfoque cualitativo permitió estudiar el fenómeno desde las subjetividades de las y los jóvenes participantes de acciones sociales, en cuanto a las elaboraciones que realizan en torno a la construcciones que se buscan identificar. Centrando el interés del estudio en la "situación misma, en la persuasión de que cada situación es única e irrepetible y de que el conjunto de condicionamientos, el contexto, es el que explica, no el que causa. (...) en este sentido la estrategia de investigación cualitativa va orientada a descubrir, captar y comprender una teoría, una explicación, un significado” (Rodríguez, G.; Gil, J. y García, E., 1999: 56).

Como herramienta para ello, se escogió la 'fotografía' como un artefacto material que aporte a trasladar aquellas nociones abstractas a espacios comunes de diálogo y acción. A la luz de ello, es que se construyeron puentes que aportaron a la discusión y operacionalización de la triada conceptual 
(juventudes, poder y lo político), en los 'sitios' interventivos que las agrupaciones juveniles reconocen como su espacio político.

Según Humberto (2000) "la fotografía pasa a representar una transcripción libre y fragmentada de una realidad a partir de una deliberación extremamente personal, un interés que puede ser apenas momentáneo por una cosa o persona, algo sencillo o cotidiano que, rescatado de su banalidad, gana un nuevo significado y puede, eventualmente, volverse una síntesis indicativa de una realidad infinita más compleja” (Visman, en Melleiro, M. y Gualda. D., 2005: 53). De esta manera el trabajo en torno a los tres conceptos centrales de la investigación, pudieron abordarse desde una dimensión material que pueda ser medio de comunicación entre las significancias y los discursos de los sujetos.

Se trabajó con nueve agrupaciones juveniles de la Región Metropolitana, las cuales declaran realizar acciones por la transformación en espacios públicos. La selección respondió a los siguientes aspectos:

- Considerarse agrupación con una intencionalidad de incidencia política.

- Desarrollar actividades de coordinación entre los participantes, las cuales se plasmen en reuniones periódicas.

- Generar acciones sociales en los espacios públicos.

- Que posean, al menos, una unidad de trabajo en la Región Metropolitana.

La construcción de la información que se presenta en este artículo, se desarrolló a través de los “Talleres Operativos”. Los talleres fueron un espacio de trabajo grupal (integrantes de la misma organización reunidos), cuyo objetivo era que las y los participantes pudieran discutir en torno a los conceptos de poder, lo político y juventudes. En estos espacios presentaron las elaboraciones personales, y aquellas que responden a la agrupación de la que son parte. Como opción metodológica se trabajó con fotografías escogidas por la investigadora, las cuales fueron un "disparador”, un “medio" que facilitó la discusión, y a la vez, aportó materialidad a los conceptos que se abordaron. La 
consigna central fue que las fotografías les ayudaran a construir su noción en torno al concepto, y que el concepto se plasmara en una fotografía.

Se utilizó un set de 20 fotografías construidas por 4 grupos temáticos:

- Imágenes de lugares públicos (plazas, edificios)

- Imágenes de sujetos (rostros de adultos mayores, adultos, jóvenes y niños)

- Imágenes históricas de movilizaciones (imágenes de las salitreras, imágenes de los años 60 y el movimiento estudiantil, imágenes de los 70 y el proyecto de la unidad popular)

- Imágenes de movilizaciones del 2011 y 2013 (imágenes de estudiantes secundarios, marchas de movimientos sociales, banderas de los partidos políticos).

Se realizaron nueve talleres con un total de 60 participantes, quienes compartían una experiencia de participación, de al menos un año de permanencia en sus respectivas agrupaciones.

A continuación se presentan los primeros hallazgos que dan cuenta de las significaciones de los tres conceptos ejes, y las vinculaciones que realizan con las fotografías presentadas en el taller.

\section{NOCIONES CONCEPTUALES TENSIONADAS CON LO CONCRETO}

Los hallazgos son construidos desde la noción de “caleidoscopio”, en donde se utilizan como elementos para construir el artefacto las ideas de poder, juventudes y lo político. De esta manera se observará e interpretarán los significados que compartieron los participantes. A la vez, heterogeneidad, flexibilidad y movimiento son los pilares de este constructo, lo cual permita revisar las imágenes y relatos que se elaboran en los espacios de taller y brindar una descripción críticas de ellos. 
En un primer ordenamiento de las significancias que se pusieron en diálogo en los talleres, es posible visualizar como las nociones se entrelazan entre concepciones naturalizadas ${ }^{5} \mathrm{y}$ aquellas que han sido reconstruidas. Cuando se refiere a la idea de naturalización, se busca expresar el uso de concepciones cotidianas, pero que al indagar sus significados no se encuentran una interiorización de los mismos, siendo casi imposible dar una definición conceptual por parte de los participantes.

Las nociones reconstruidas son aquellas que utilizan los conocimientos cotidianos, pero las re-elaboran desde las reflexiones conceptuales y prácticas que han desarrollado desde sus experiencias. Aquí se aprecia un trabajo de deconstrucción que posibilita procesos de discusiones al interior de las agrupaciones, como también las que se pueden desarrollar entre las mismas. Así, uno de los ejes del caleidoscopio se aprecia: heterogeneidad de las comprensiones desplegadas por los participantes.

Siguiendo con la metáfora del caleidoscopio, un segundo elemento esencial es la flexibilidad, la cual se aprecia en las formas de significar las tres nociones que aborda esta investigación. Las y los participantes, presentan sus construcciones, las comparten entre sus "compañeros/as" de agrupación, discutiendo las ideas centrales sin potenciar la hegemonía de un solo discurso. Hay divergencia y disenso, pero desde la flexibilidad se producía un puente de discusión y reflexividad. La posibilidad de permearse a los conocimientos y creencias de sus compañeros de agrupación, es una característica común entre los participantes de los talleres; lo que no implica que se olviden de sus propias construcciones, sino que están en una disposición de discutir, construir y reconstruir los sentidos que se impregnan en las acciones de sus apuestas.

\footnotetext{
${ }^{5}$ La idea de naturalización hace referencia a la utilización de conceptos sin tensionar su significado con los contextos, historia, cultura, entre otras dimensiones, lo que provoca una reducción conceptual que se plasma en un vacío de contenidos.
} 
En cuanto al movimiento (como tercer elemento central del caleidoscopio) se aprecia de manera particular en dos ejercicios específicos: en las traslaciones de las ideas conceptuales a imágenes fotográficas, y desde las fotografías a conceptos; como también en la puesta en común que se produce en el dialogo entre los integrantes. Parten desde nociones específicas, se ponen frente a todos, y desde ese entramado vuelve a ser procesada por cada sujeto presente. Aquí el movimiento es un ejercicio constante, que va y viene en distintos planos, cuya impronta refleja construcción, deconstrucción y reconstrucción.

La apuesta del caleidoscopio permite revisar las construcciones de las nociones centrales de esta investigación posibilitando visualizar diversas imágenes que aparecen y mutan según la posición desde dónde se inicie el ejercicio del reconocimiento. A continuación se presentan las reconstrucciones grupales que se materializaron en los diálogos con los participantes.

El primer concepto que se trabajó fue el de “juventudes”. Se les pidió que eligieran, del grupo de fotografías, aquellas que aportara a su propia noción, ya sea por similitud o diferencia. La idea de disparador era central para poner en común sus construcciones.

Los grupos de fotografías más utilizadas para este concepto fueron aquellas que presentaban:

- Imágenes históricas de movilizaciones

- Imágenes de movilizaciones del 2011 y 2013

Los elementos que llevaron a elegir estas fotografías se centraron en una diada de ideas “jóvenes” y “transformación”; las imágenes les ayudaban a presentar los elementos que les permitía indicar que las actorías sociales se vinculan a procesos de cambios, los cuales apuntan a un cuestionamiento completo que tensionan sus experiencias cotidianas con las características estructurales de las sociedades contemporáneas. 
"siento que es como, a título personal de una conversación que viene siendo parte de hartos compañeros y compañeras, como probablemente el lugar donde aparece como un cuestionamiento de la sociedad chilena de los últimos 25 años, aparece desde esta actor: son sujetos jóvenes que hacen el cuestionamiento desde el sistema educativo al Chile Neoliberal...”. (Taller 2)

Elaboran nociones que se basan en la heterogeneidad de sujetos que construyen la categoría de “juventudes", la cual, es vinculada a procesos de análisis, reflexión, y acciones que se ponen de manifiesto en las experiencias personales y las compartidas en los espacios grupales.

"la juventud el concepto más grande que tiene es la diversidad... diversidad de culto, como diversidad cultural... más fuerza” “caer en el esencialismo, como de que todos los jóvenes son o tienen una postura política crítica, no sé si es así, yo creo que los jóvenes son súper diversos”. (Taller 9)

Si bien no existe un consenso en indicar que los elementos constitutivos de dicha categoría son “únicamente” los mencionados, sí los identifican como claves de comprensión tanto para las expresiones que visualizan como también para los procesos de trabajo colectivo en los que se involucran.

Como se indicó, hay una predilección al elegir fotografías que se relacionan a los movimientos sociales tanto actuales como históricos, se destaca la relación entre juventudes y transformaciones desde la capacidad que tienen los sujetos involucrados de no detenerse (incluso de no asustarse) frente a posibilidades de generar nuevas opciones de bienestar social. Destacan que esta “lucha” por alcanzar otro estado, no la piensan ni la abordan de manera individual, sino que desde las imágenes, destacan las luchas históricas que los han puesto como protagonistas. 
Al momento de ahondar en la “idea” conceptual de juventudes, confluyen elaboraciones que se acercan a definiciones clásicas como también aspectos de reconstrucciones contemporáneas. Aparece como ejercicio natural el indicar que "la” juventud es un momento vital, que abarca un tramo etáreo, y aquellos elementos que los visualiza como “ángeles” o “demonios” (según sea el prisma). Lo anterior se puede comprender al revisar los elementos adultocentristas ${ }^{6}$ que están presentes en nuestras sociedades, en donde la reproducción de estas creencias es transversal. Las y los jóvenes, también son actores involucrados y creyentes activos de estas miradas.

Sin embargo, en los espacios de los talleres, también se nutrieron desde las miradas que desclasifican esas creencias y las nuevas nociones de lo social que van incorporando. Se reconoce como experiencia vital, pero no por ello con un inicio y/o término determinado por los años que se cumplen, más bien se incluyen diversos saberes que complejizan las nociones identificándola (incluso) como una categoría construida que da cuenta de sujetos sociales reflexivos y cuestionadores, que desde su situación vital, revisan, deciden y actúan, apostando en ellos sus creencias y habilidades. Incorporan elementos culturales y sociológicos, que posibilitan un acercamiento al concepto, usando un caleidoscopio que se aleja de las etiquetas sociales, nociones rígidas, y encasilladas a una homogeneidad que no se aprecia.

“Lo que es juventud de hoy en una palabra es una queja...por ejemplo con el tema de la educación, mira lo que hacen en las marchas...le tienen miedo a la responsabilidad, independiente a las consecuencias es buscar su objetivo, no piensan en los otros...en las marcha se ve, robos,

\footnotetext{
${ }^{6}$ Cuando se utiliza el concepto de adultocentrismo se hace referencia a una matriz teórica, que considera aquellos aspectos 'valorados' por las sociedades desde las lógicas de producción, moral, cultura y elementos homogéneos que han sido aceptados por aquellos sujetos que son considerados como adultos. La adultez ha sido reconocida y relevada desde distintos cánones socioculturales a lo largo de la historia contemporánea, pues se construye en estrecha relación con las características del momento en que se utiliza. Es una valoración por el mundo adulto, invisibilizando (y/o negando) las juventudes (Duarte, 2015).
} 
delincuencias ¿y se hacen cargo? Son abusadores simplemente por ser número y arrasar con lo que encuentre”. (Taller 5)

“pero igual la juventud no tiene por qué responder a una categoría o... como decían del espíritu joven creo que es algo que se lleva siempre, el espíritu del que levanta un movimiento social o un espíritu crítico”. (Taller 1)

Los diálogos confluyen en esta traslación constante entre la caracterización de las juventudes como un momento vital que encierra en sí mismo las caricaturas de lo bueno y lo malo de las imágenes societales, como también con aquellas formas de construirlas que aportan a un reconocimiento de su constitución como actorías que movilizan transformaciones.

Cuando se incorpora en la discusión la pregunta por la noción de “poder”, la elección de las fotografías se centra entre:

- Imágenes de lugares públicos (plazas, edificios)

- Imágenes históricas de movilizaciones

- $\quad$ Imágenes de movilizaciones del 2011 y 2013

Como se aprecia hay similitudes en las elecciones de las imágenes, particularmente entre aquellas que representan movilizaciones como mensaje central de la fotografía. Esta elección es la que abre una conversación que permite entrelazar dos nociones centrales que permiten comprender la idea de actoría juvenil que se ha presentado.

"el concepto de juventud, que también lo encuentro muy asociado a la idea de poder, precisamente porque la juventud ha sido creo yo, es súper como estigmatizada, como "el rebelde”, “el distinto”, "el que no se adapta” a la norma establecida, al orden que a todos nos acomoda y en el cual hemos convergido como sociedad, etc., y aquí hay un montón de gente sentada haciendo todo lo que los chilenos hacen en una fiesta y que lo hacen sentados, mientras una es como la que sale a bailar, 
entonces ahí me parece que hay una actitud de esta banca juvenil que es súper irrelevante, por eso me parece bonito”. (Taller 6)

Esta vinculación da cuenta de una mirada particular de las construcciones de poder que se están realizando al interior de estas agrupaciones. Hay una tendencia a concebirla como una combinación de fuerzas provenientes de la interacción entre sujetos en los espacios públicos. De esta manera se reconoce que la actoría posee como uno de sus sustentos una idea de poder que hace referencia a la capacidad de reflexión, autonomía y decisión que se posee de manera individual y se manifiesta en vínculo con los otros.

"Si bien, como en términos discursivos creo que tenemos como cierta coincidencia eeeh, yo lo visualizo más como en tener la capacidad de tomar ciertas decisiones, o sea, el poder te permite decidir el rumbo en torno a ciertos aspectos de cómo organizar la sociedad, a veces incluso como de qué temas a abordar tiene que ver como un tema de poder en la sociedad”. (Taller 3)

Así mismo, un segundo nivel de reconocimiento está puesto en las estructuras que 'ostentan poder'. Este reconocimiento lo ligan a la tradición demócrata en que la sociedad chilena se ha construido. Hay una vinculación importante entre Estado y poder, pues éste (desde la referencia histórica que hacen los participantes), es el encargado de administrarlo. De esta forma se hace referencia a la capacidad de administrar poder y utilizarlo para un ordenamiento según los sistemas imperantes. Esta construcción trae consigo una concentración de decisiones en manos particulares, y despojando de dicha opción a otros.

“El poder, el Congreso, de todas maneras. Los partidos políticos lo que hacen es buscar el poder para influir con ideas, influir de alguna manera en los países, en la sociedad en los Congresos, ahí se dictan las leyes que finalmente son las que nos rigen y estas leyes de alguna forma 
vienen con muy buenas intenciones, pero muy mal implementadas por causas ideológicas y ahí de todas maneras en la imagen que mejor representa el poder". (Taller 5)

Ambas construcciones conviven en el sistema de significaciones de los participantes, es aquí donde se construye uno de los hallazgos relevantes de este proceso investigativo. La noción de poder ha ido trasladando su campo explicativo de los espacios macros, estructurales a los ámbitos que podemos reconocer como los micros espacios, expresando su existencia en forma de atributo de los sujetos. Aquí la mirada Foucaultiana se presta como una posibilidad para revisar como las subjetividades van tensionando los campos estructurales y así, de construyendo sistemas de comprensiones 'dadas'.

"el poder no lo considero como algo estático, sino como un elemento que fluye, el poder lo pueden tener algunas veces los dominados y después puede fluir hacia los... ahh perdón de los dominantes a los dominados, entonces puede fluir y encuentro que por mi adscripción política hacia el feminismo las mujeres ahora están disputando el poder de una forma súper... ehh especial e histórica en Chile, después de la dictadura estamos volviendo a re-articularnos nacionalmente y es una cosa que nos va a dar muchas más fuerza que estar inscritos en microespacios que pueden ser colectivos, ya estamos en democracia y tenemos las oportunidad y tenemos que tomarlas y me parece súper bueno que el movimiento feminista sea un movimiento clave pa' la disputa del poder de los escenarios políticos que buscan la transformación estructural de la sociedad acá en Chile, sobretodo en que somos un contexto neoliberal”. (Taller 8)

La noción de poder está inserta en las constituciones de sujetos y actores que componen los tejidos sociales y por ende los espacios de lo político. Lo tangencial de dicha constitución se aprecia en las estrategias de intervención que las agrupaciones asumen como propias. Dichas estrategias se basan en 
creencias transversales en sus propias elaboraciones, por lo tanto es parte de su desafío el ponerlas en común para que los diversos actores sociales las reconozcan como alternativas atractivas en pos de la transformación.

Lo anterior no implica que se hayan superado los procesos de naturalización de un aspecto de la idea de poder: dominación. Los participantes reflexionan que si no están en actitud de reflexión, con los códigos éticos traduciendo sus acciones, es posible volver a caer en la tentación histórica de la dominación de espacios de creencia y operacionalización, anulando y/o invisibilizando la presencia del disenso como eje clave de lo contemporáneo. He aquí donde se marca un hallazgo particular, el cual es la presencia de una memoria histórica que moviliza a no repetir patrones que se han aprendido e incorporado desde los legados históricos de la región, y particularmente de Chile. Se insiste en la necesidad de promover acciones que abran la puerta a la diferencia. Apuntan que no es una actitud de tolerancia, sino que de un respeto traducido en disenso.

El concepto de poder entendido como atributo requiere actos de interrelación, y para conjugarse con elementos estructurales, las y los participantes visualizan como el espacio de lo político un escenario esencial para identificar esta noción. Aquí se incorpora a la discusión la pregunta por “lo político”.

Frente a la pregunta, los participantes se inclinaron (en la elección de fotografías) por los grupos que reflejaban:

- Imágenes de lugares públicos (plazas, edificios)

- Imágenes históricas de movilizaciones

Las elecciones que se realizaron en torno al primer grupo de fotografías, se basaron en el conjunto de significados que le dan a los espacios públicos. Se indica que lo político tiene una cercanía a lo público, ya que lo entienden como aquellos escenarios comunes para todos los integrantes de la sociedad. Aquí se aprecia un énfasis por reconocer lo público como cualquier espacio de 
encuentro entre sujetos diversos. Hay un acercamiento a la idea de ciudadanía desde los espacios comunes que ofertan los barrios.

"En las fotos de lo Político, se ve que en la plaza la gente está haciendo ejercicio, una cosa que yo debería hacer y un par de personas de la tercera edad. Yo creo que tenemos que enfocarnos en lo político a trabajar por las personas, por los espacios públicos, por la sociedad civil, por recuperar la dignidad de las personas y yo creo que hay que mirar esa fotografía en materia política”. (Taller 5)

Lo político, para los participantes, también es significado como aquellos espacios que si bien en "esencia" son comunes, han sido utilizados para gestionar los poderes estatales y de la ciudadanía; sin embargo no cuentan con la representatividad ni sintonía con los sentidos de los integrantes de la sociedad. Reconocen estructuras históricas, pero cuestionan su capacidad de representatividad y efectividad para el desarrollo del bien común.

"El Congreso, que simplemente para mi es una institución donde se ejerce el poder, independiente de la necesidad, hoy día no se refleja la necesidad de la ciudadanía, o sea está muy separado la realidad con lo que pasa adentro, por eso es poder puro no más”. (Taller 1)

Esta conjugación de significados va tejiendo posibilidades de redefinir las nociones que le brindan a lo político, pues si bien aún hay una tendencia por igualarlo a la política, ven que lo que los moviliza va más allá que un sistema de gobierno específico. Desde estos enfoques se aprecia una valoración por la construcción de un proyecto distinto construido por todos desde el encuentro y reconocimiento de todos/as.

“con respecto al concepto de lo político, elegí la imagen (...) bueno la elegí porque trae en ella un significado en el lienzo que dice "crear poder popular" con una serie de manifestantes tras de él, esta fotografía lo identifico con lo político principalmente yo considero que 
lo político es cualquier proyecto que considere una comunidad que es idóneo para poder organizar la sociedad en el futuro, súper simple y encuentro que en los 70's las organizaciones políticas que estaban en ese momento justamente estaban haciendo... estaban dándole vida y carne a lo que es la política y no entendían formas de organización de la misma como puede ser un sistema de gobierno que puede ser el presidencialismo que son en verdad formas más que el fondo y a lo mejor generaciones recientes como las de nosotros pueden entender que eso es la política siendo que la política se inscribe en ámbitos que son mucho más amplios que ocupar un edificio que se llame La Moneda, obviamente como que es mucho más extenso”. (Taller 8)

"lo político es un proceso como colectivo en donde creo yo que cada una de esas personas toma parte como de la decisión de manifestarse ehh... incluye también el plano privado que muchas veces, o sea quizás es un lienzo y está en una parte muy pública, pero incluye una temática que muchas veces se desaloja de qué es lo político y que me gusta cómo hacer énfasis en eso, son nuestras vidas privadas, nuestros mundos privados lo que llevan... que es pura puja y relación de poderes dentro del ámbito privado”. (Taller 3)

Lo político también se encuentra dentro del sistema de creencias que ha iniciado un proceso de desnaturalización por parte de los participantes, puesto que la similitud con la política, ya es una construcción que incomoda y esperan brindar otros horizontes comprensivos para ellos. Desde este abanico de combinaciones se apuesta no sólo por un sistema diferente, sino que por una construcción social distinta.

La elaboración de los tres conceptos se entrelaza para dar cabida a la comprensión en torno a las estrategias de transformación que las agrupaciones asumen como propias. Desde ellas es que se despliegan una conjugación de 
elementos simbólicos como materiales que se ponen en movimiento en pos de sus tránsitos.

\section{Conclusiones}

A partir de los elementos presentados, se hace posible construir algunas ideas fuerzas que aparecen como ejes transversales del proceso investigativo, pero también, se movilizan hacia aspectos reflexivos particulares que se desprenden de los temas abordados.

Las nociones conceptuales que las y los participantes abordan no son hegemónicas. Más bien, conversan entre sí en pos de las transformaciones que buscan construir. Se aprecia un aprendizaje en torno a la inclusión del disenso. Hay divergencia entre los mismos integrantes de la agrupación; sin embargo esta incorporación de heterogeneidad se limita al interior de las agrupaciones, aún no encuentra proyección para ponerla en el espacio común con otras entidades, y se tensiona cuando estas agrupaciones persiguen horizontes diferentes a los propios.

Ahora, en torno a las nociones de juventudes se visualiza una coexistencia, entre aquellas miradas que se desprenden de la matriz adultocéntricas, con construcciones que devienen de reflexiones que apuestan a superar esa inmovilidad. Aquí, uno de los hallazgos interesantes, se vinculan a las miradas contemporáneas que se entrelazan con las nociones de capacidades y actoría de las juventudes en un presente inmediato, dejando atrás la idea de tránsito hacia la adultez. Junto a ello, la mirada contemporánea ha teñido los significados de diversos actores, por lo tanto no son construcciones cerradas de un grupo específico. La combinación de miradas se aprecia en el conjunto de sujetos involucrados.

La idea de poder transita desde concepciones contemporáneas a construcciones conservadoras y dominantes, para luego volver a miradas 
horizontales. Hay un desarrollo de conciencia en pos de un movimiento emancipador al respecto. Reconocer 'poder' como atributo y no solo como sistema de dominación, posibilita desde las significancias de los participantes, una posibilidad de reconstruir aspectos de lo social desde la lógica del respeto y el reconocimiento.

Lo anterior se entrelaza con lo construcción de lo político, que desde las y los participantes, transita entre conceptos cargados de imágenes de lo común, lo compartido, lo de todos (espacios), escenarios de encuentros y des-encuentro, pues en ellos se ponen en movimientos las transformaciones, como también, aquellas elaboraciones que los asocian a sistemas de gobierno, de orden, incluso, de partidos.

De esta manera, los dispositivos de intervención conjugan el desarrollo de los conceptos, y presenta desde ahí estrategias de intervención que cuestiona la transformación y se compromete con ella. Juegan una apuesta de traslación que, más que por optar por una sola imagen, busca incluir las diferencias al interior de una misma elaboración. Conceptos y acciones transitan en función de los movimientos que los actores desarrollen en pos de las transformaciones.

\section{REFERENCIAS:}

Carballeda, A. (2002). La intervención en lo Social: Exclusión e integración en los nuevos escenarios sociales. Buenos Aires: Paidós.

Cazzaniga, S (2005). Hilos y Nudos, La formación, la intervención y lo político en trabajo social. Buenos Aires: Editorial Espacio.

De Robertis, C. y Pascal, Henri (2007). La intervención colectiva en el trabajo social: la acción con grupos y comunidades. Buenos Aires: Lumen.

Duarte, K. ¿Juventud o Juventudes? Versiones, trampas, pistas y ejes para acercarnos progresivamente a los mundos juveniles. Revista Pasos No 93. San José, Costa Rica: Departamento Ecuménico de Investigaciones.

Foucault, M (2002). Micro física del poder. $3^{\circ} \mathrm{ed}$. Madrid: Las Ediciones de la Piqueta.

Foucault, M. (1984). Estrategias de poder. París: Ediciones Gallimard. 
Healy. K. (2001). Trabajo Social: Perspectivas Contemporáneas. Madrid: Ediciones Morata.

Matus, T. (1999). Propuestas contemporáneas en Trabajo Social: Hacia una intervención polifónica. Buenos Aires: Espacio.

Mouffe. C. (200/). En Torno a lo Político. Argentina: Fondo de Cultura Económica.

Pelegrí, X. (2004). El poder en el trabajo social: una aproximación desde Foucault. Cuadernos de Trabajo Social, Vol.17 (2004): pp. 21-43. Universidad de Lleida.

Recepción de artículo: octubre 2016

Aceptación de artículo: enero 2017 